\title{
Arteriovenous Malformation of the Corpus Callosum associated with Persistent Primitive Trigeminal Artery \\ -Case Report-
}

\author{
Akira UCHINO, Masayuki MATSUNAGA* and Masato OHNO \\ Departments of Radiology and *Neurosurgery, Kyushu Rosai Hospital, \\ Kitakyushu, Fukuoka
}

\begin{abstract}
A 16-year-old girl with a large, ruptured arteriovenous malformation (AVM) of the corpus callosum was studied by computed tomography and angiography. The relatively large nidus of the AVM was located mainly in the anterior portion of the corpus callosum, and there was a smaller nidus in the splenium. She also had a persistent primitive left trigeminal artery (PTA). This is the first reported case of an AVM with extensive callosal involvement associated with a PTA. She underwent radiation therapy and remained asymptomatic for 2 years thereafter.
\end{abstract}

Key words: arteriovenous malformation, corpus callosum, persistent primitive trigeminal artery

\section{Introduction}

So-called "callosal arteriovenous malformations" (AVMs) are not truly uncommon, but extensive AVMs involving the entire corpus callosum are rare. ${ }^{13)}$ Persistent primitive trigeminal artery (PTA) is the most frequent anomaly of carotid-basilar anastomoses. Its reported angiographic incidence is $0.2 \% .^{1)}$

\section{Case Report}

This healthy, 16-year-old girl experienced sudden onset of severe headache and vomiting. Neurological examination revealed nuchal rigidity, papilledema, and spasticity of the extremities. She was, however, alert. The clinical diagnosis was subarachnoid hemorrhage.

A precontrast computed tomographic (CT) scan demonstrated a hematoma in the lateral and third ventricles and a slightly hyperdense, abnormal structure in the midline (Fig. 1 upper). This abnormal structure as well as the vessels were markedly enhanced on a postcontrast scan (Fig. 1 lower). The

Received December 11, 1987; Accepted October 6, 1988 diagnosis was ruptured AVM.

Left internal carotid arteriography showed a PTA and the large nidus of an AVM in the anterior portion of the corpus callosum and in the related medial portions of the frontal lobes. It also disclosed a small nidus of the AVM in the splenium of the corpus callosum. The larger nidus was fed by numerous branches of the left anterior cerebral artery and the smaller nidus by the posterior pericallosal artery (Fig. 2 upper). Both nidi were drained mainly by subependymal veins. The blood flow of the AVM was markedly increased, so that blood entered the basal veins of Rosenthal and the cortical veins bilaterally in a retrograde fashion (Fig. 2 lower). Right internal carotid arteriography demonstrated part of the larger nidus by cross flow via the anterior communicating artery. Left vertebral arteriography demonstrated the smaller nidus.

Before its rupture she had had no symptoms related to the AVM, such as mental retardation, seizure, frequent headache, or heart failure.

Neither surgery nor embolization was performed. Telecobalt was administered in a total dose of $40 \mathrm{~Gy}$. She remained asymptomatic for 2 years after irradiation, and postcontrast CT showed no significant changes during this time. 

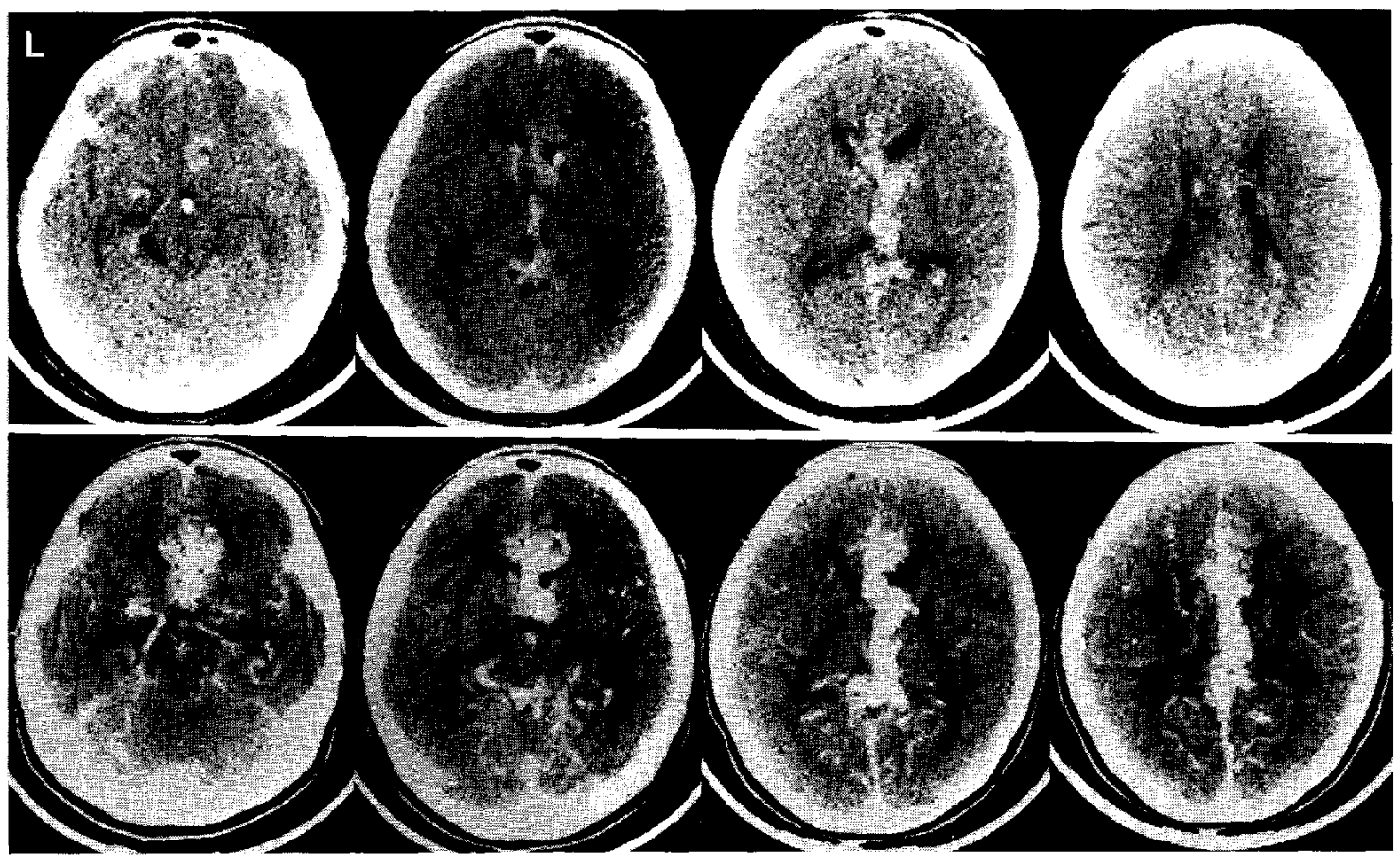

Fig. 1 upper: A precontrast CT scan, in which a hematoma is observed in the lateral and third ventricles. A slightly hyperdense, abnormal structure is also seen in the midline. lower: A postcontrast CT scan, showing marked enhancement of the midline abnormality as well as the vessels. Many cortical veins are dilated, indicating a collateral circulatory network.

\section{Discussion}

The so-called "callosal AVM" is not truly a rare lesion. Yasargil et al. ${ }^{13)}$ reported its incidence to be $15 \%$ of operated cerebral AVMs. Garza-Mercado et al. ${ }^{3)}$ reported one case of callosal AVM among 19 children and adolescents with cerebral AVMs. Callosal AVMs are classified as involving 1) the anterior portion (genu); 2) the middle portion (corpus); or 3) the posterior portion (splenium). ${ }^{13)}$ The splenium is the most frequent site of callosal AVMs. ${ }^{12)}$ Our patient's lesion, which contained two separate nidi in the anterior and posterior portions of the corpus callosum, is an extremely rare type of AVM. ${ }^{13)}$

Deep-seated cerebral AVMs, including callosal AVMs, have a high incidence of intracranial hemorrhage. ${ }^{81}$ Vinuela et $a l^{10)}$ suggested that impaired venous outlets cause elevation of venous pressure, making the nidus of the AVM prone to rupture. In our case, the internal cerebral vein was markedly dilated due to increased blood flow. However, the wall of the straight sinus was so hard that it was not dilated. The overflowing blood then made retrograde entry into the basal veins of Rosenthal and the cortical veins bilaterally. Venous pressure in the deep venous system was therefore thought to be elevated.

Cone et al. ${ }^{2)}$ reported the typical CT findings of callosal AVMs to be intraventricular hemorrhage with an irregular area of contrast enhancement in the corpus callosum. These features were present in our case.

The choice of therapy for our patient was difficult. Surgical removal of AVMs is possible but, because of their locations, may result in significant neurological deficits. ${ }^{6)}$ The feeding arteries are numerous and small, and embolization is not indicated. Although radiation therapy is usually ineffective, Tognetti et al..$^{9)}$ reported a case of a parietal AVM that was successfully managed with conventional irradiation. We therefore selected to try radiation therapy. No significant changes have been detected on $\mathrm{CT}$, but the patient has been asymptomatic for 2 years.

PTA is the commonest anomaly of carotid-basilar anastomosis, having a reported angiographic incidence of $0.2 \% .{ }^{1)}$ Most PTAs are detected incidentally during carotid arteriography, and they usually are of minimal clinical significance. However, PTA may cause trigeminal neuralgia, ${ }^{5}$ oculomotor paralysis, and other cranial nerve dysfunction syndromes. Aneurysms of PTAs are well known. In a review of 


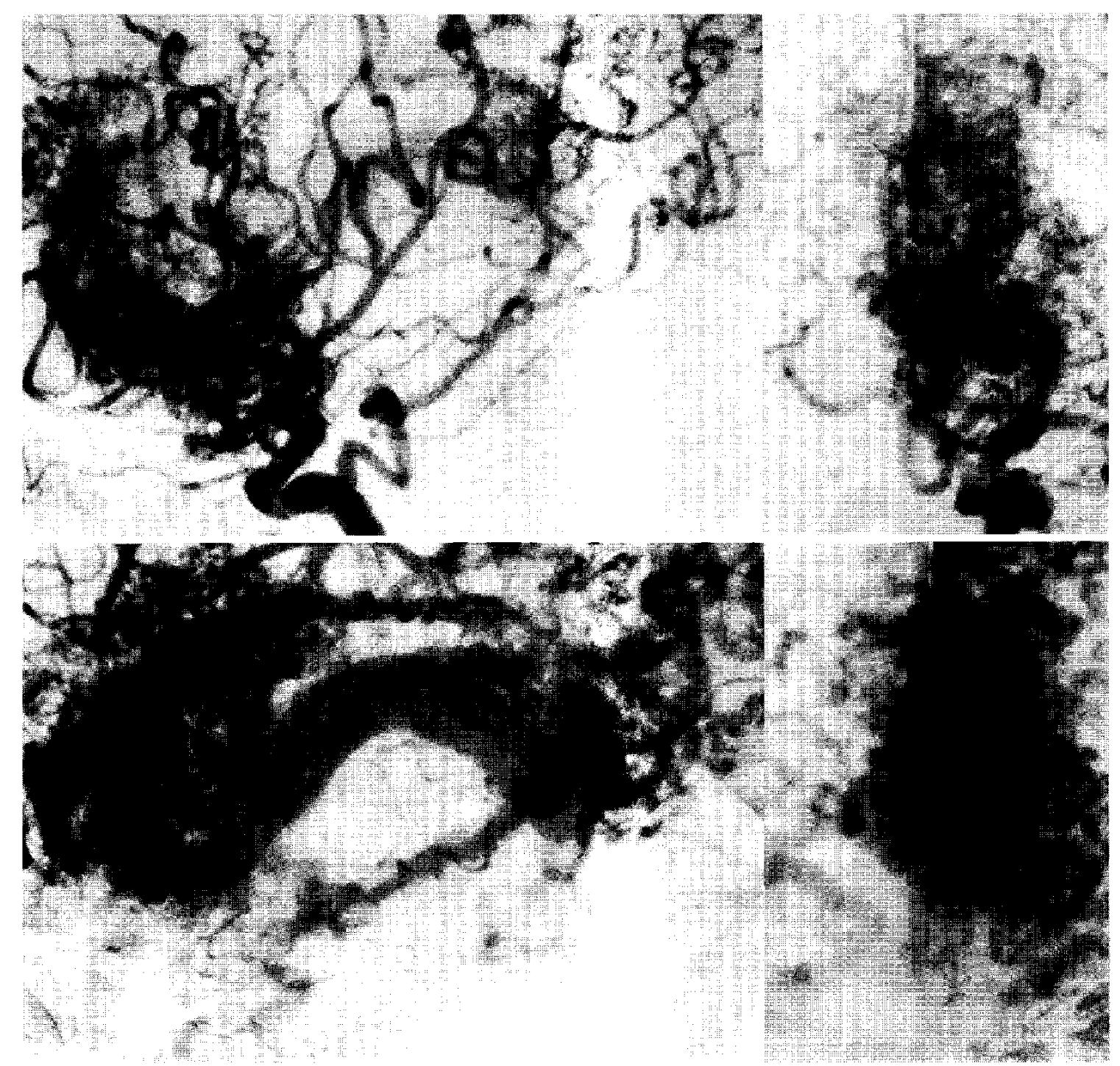

Fig. 2 Left internal carotid arteriograms. upper: Arterial phase. The larger nidus of the AVM is located in the anterior portion of the corpus callosum and in the related medial portions of the frontal lobes. The smaller nidus is situated in the splenium of the corpus callosum, and the PTA was incidentally imaged. lower: Venous phase. The draining vessels of both nidi are subependymal veins. The internal cerebral vein is markedly dilated, but there is no increase in the diameter of the straight sinus. Therefore, there is retrograde flow into the basal veins of Rosenthal and the cortical veins.

the literature, George et al..$^{4)}$ found four PTA aneurysms among 232 cases of PTA.

In his review, Agnoli ${ }^{13}$ found 18 cases of AVM among 400 cases of PTA. Thus, there is a relatively high rate $(4.5 \%)$ of AVM among PTA patients. Wakai et al. ${ }^{11)}$ reported a case of a small AVM associated with a PTA. To our knowledge, however, ours is the first reported case of an extensive callosal AVM associated with PTA.

\section{Acknowledgment}

We are grateful to Walter J. Russell, M.D., D.M.Sc. of the Radiation Effects Research Foundation, Hiroshima, for his valuable suggestions.

\section{References}

1) Agnoli AL: Vascular anomalies and subarachnoid haemorrhage associated with persisting embryonic 
vessels. Acta Neurochir (Wien) 60: 183-199, 1982

2) Cone JD, Maravilla KR, Cooper PR, Diehl JT, Clark WK: Computed tomography findings in ruptured arteriovenous malformations of the corpus callosum. J Comput Assist Tomogr 3: 478-482, 1979

3) Garza-Mercado R, Cavazos E, Tamez-Montes D: Cerebral arteriovenous malformations in children and adolescents. Surg Neurol 27: 131-140, 1987

4) George A, Lin JP, Morantz RA: Intracranial aneurysm on a persistent primitive trigeminal artery. $J$ Neurosurg 35: 601-604, 1971

5) Kempe LG, Smith DR: Trigeminal neuralgia, facial spasm, intermedius and glossopharyngeal neuralgia with persistent carotid-basilar anastomosis. $J$ Neurosurg 31: 445-451, 1969

6) Luessenhop AJ, Rosa L: Cerebral arteriovenous malformations. Indications for and results of surgery, and the role of intravascular techniques. $J$ Neurosurg 60: 14-22, 1984

7) Madonick MJ, Ruskin AP: Recurrent oculomotor paresis. Paresis associated with a vascular anomaly, carotid-basilar anastomosis. Arch Neurol (Chicago) 6: 353-357, 1962

8) Stein BM: Arteriovenous malformations of the medial cerebral hemisphere and the limbic system. $J$ Neurosurg 60: 23-31, 1984

9) Tognetti F, Andreoli A, Cuscini A, Testa C: Suc- cessful management of an intracranial arteriovenous malformation by conventional irradiation. $J$ Neurosurg 63: 193-195, 1985

10) Vinuela F, Nombela L, Roach MR, Fox AJ, Pelz DM: Stenotic and occlusive disease of the venous drainage system of deep brain AVM's. $J$ Neurosurg 63: $180-184,1985$

11) Wakai S, Ueda $Y$, Nagai $M$ : Cerebrovascular anomalies associated with primitive trigeminal artery. Report of three cases. Neurol Med Chir (Tokyo) 27: 633-636, 1987

12) Yasargil MG, Jain KK, Antic J, Laciga R: Arteriovenous malformations of the splenium of the corpus callosum: Microsurgical treatment. Surg Neurol 5: $5-14,1976$

13) Yasargil MG, Jain KK, Antic J, Laciga R, Kletter G: Arteriovenous malformations of the anterior and the middle portions of the corpus callosum: Microsurgical treatment. Surg Neurol 5: 67-80, 1976

Address reprint requests to: A. Uchino, M.D., Department of Radiology, Kyushu Rosai Hospital, 1-3-1 Kuzuhara-takamatsu, Kokuraminami-ku, Kitakyushu, Fukuoka 800-02, Japan. 